\title{
EXPERIÊNCIA DE EDUCAÇÃO CONTINUADA A DISTÂNCIA: a visão do aluno e do aluno/tutor no curso de Gráfica Digital
}

\author{
Luisa Rodrigues Félix \\ Janice de Freitas Pires** \\ Adriane Borda Almeida da Silva*** \\ Neusa Rodrigues Félix****
}

\section{Resumo:}

Neste trabalho descreve-se experiências de ensino/aprendizagem, na modalidade de Educação a Distância (EaD), via Internet, que permeiam o curso de pós-graduação de Especialização em Gráfica Digital, da Universidade Federal de Pelotas. Este curso, que já promovia algumas atividades na modalidade assíncrona, realiza a partir do primeiro semestre de 2005, uma experiência totalmente à distância, mesclando situações síncronas e assíncronas. Promove-se a discussão sobre a metodologia adotada para a estruturação do curso para esta modalidade, que passou a caracterizar um agente diferenciado: o aluno/tutor. Registram-se as percepções do aluno e do aluno-tutor, envolvidos neste caso, confrontando-as com referenciais teóricos que vêm apoiando experiências em $\mathrm{EaD}$, a fim de incrementar os dados para a pesquisa nesta área.

Palavras Chave: Ensino a Distância, Gráfica Digital, aluno-tutor.

\section{EXPERIENCE OF CONTINUED DISTANCE LEARNING: the point of view of student and student/tutor of the Digital Graphic Course}

\begin{abstract}
:
In this study are described the teaching/learning experiences, in the Distance Learning through the Internet modality in the pos-graduation course in Digital Graphics from the Universidade Federal de Pelotas. This course, which already promoted some activities in the asynchronous modality, carries out starting from the first semester of 2005, a totally distance experience, mixing synchronous and asynchronous situations. The discussion is promoted, about the methodology adopted for the course structured for this modality, which characterized a different agent: the student/tutor. The perceptions of the student and of the student/tutor involved in this case are registered, confronting them with the referential theories that support the Distance Learning experiences, in order to increment the data for research in this area.
\end{abstract}

Keywords: Distance Learning, Digital Graphics, student/tutor.

\footnotetext{
arquiteta, Especialização em Gráfica Digital,-UFPEL, estudante, isa_luls@mail.com

** arquiteta, Especialização em Gráfica Digital,-UFPEL, estudante/tutora, janice_egd@ yahoo.com.br

*** arquiteta, doutora,UFPEL, professora adjunto,adribord@ufpel.tche.br

**** arquiteta, doutora,UFPEL,professora titular, neusarf@ufpel.tche.br
} 


\section{Introdução:}

O Curso de pós-graduação, de Especialização em Gráfica Digital, da Universidade Federal de Pelotas tem investido na possibilidade de flexibilizar a forma de promoção das situações de ensino/aprendizagem nesta área do conhecimento.

Considera-se que a Gráfica Digital cada vez mais amplia sua área de abrangência, subsidiando campos do conhecimento que necessitam utilizar a imagem e os modelos digitais como potencializadores de processos de informação e comunicação.

Oferecer uma formação específica em Gráfica Digital, para profissionais oriundos das distintas áreas do conhecimento, é um desafio, partindo-se da necessidade de conceitos prévios, principalmente relativos à geometria e à física.

Aposta-se na modalidade educativa à distância, como alternativa para possibilitar o acesso de diferentes profissionais a este conhecimento, por trazer a proposta de adequação e respeito ao ritmo de construção do conhecimento individual, compatibilizando horários e locais de estudo. E, de acordo com a infra-estrutura disponível, de estratégias e materiais didáticos, pode possibilitar que o estudante parta de diferentes níveis de aprofundamento, compatível com sua formação prévia.

Nesta perspectiva, este Curso, busca promover situações didáticas que possam estar disponíveis a qualquer tempo e lugar, no contexto da Internet, oferecendo um espaço para a formação continuada, de atualização para profissionais específicos da área de Expressão Gráfica assim como para aqueles que objetivem ampliar sua formação, abarcando também a área referida.

Nos últimos anos se tem promovido algumas atividades na modalidade à distância, de maneira assíncrona que ampliam o espaço de trabalho das disciplinas presenciais. Estas situações foram incrementando o processo de produção de infra-estrutura para a viabilização de um Curso na modalidade à distância. A partir do primeiro semestre de 2005, realiza-se uma primeira experiência totalmente à distância, mesclando situações síncronas e assíncronas.

Neste trabalho parte-se da descrição da metodologia adotada para estruturar as disciplinas do curso para serem disponibilizadas na modalidade à distância, centrandose tanto nas questões pedagógicas como tecnológicas.

Para contextualizar o experimento, inicialmente, destacam-se as especificidades do Curso, referindo-se ao perfil do aluno e às particularidades de cada disciplina, em função da natureza do saber trabalhado e, principalmente, das estratégias didáticas adotadas pelo corpo docente.

Em um segundo momento ressalta-se a caracterização do agente "aluno-tutor", que participa de uma situação presencial e, paralelamente, faz parte da equipe do projeto de estruturação e implementação da experiência em EaD nas disciplinas nas quais o professor necessita ser ambientado na plataforma de ensino aprendizagem adotada (TELEDUC).

Logo, sob o ponto de vista do aluno, e do aluno-tutor, são destacados os pontos positivos e negativos da experiência, buscando-se confrontá-los com referenciais teóricos que tem apoiado experiências em EaD.

Este relato e reflexão pretendem incrementar os dados extraídos de experiências concretas, relativos à visão do aluno frente ao ensino/aprendizagem mediado por tecnologia e, principalmente, provocar a discussão sobre a metodologia adotada, que passou a caracterizar um agente diferenciado: o aluno/tutor.

\section{Especificidades do Curso de Especialização em Gráfica Digital}

O curso de Especialização em Gráfica Digital, oferecido pelo Departamento de Desenho Técnico e Gráfica Computacional da Universidade Federal de Pelotas, tem 
suas origens em 1999, quando foi criado o Curso de Especialização em Desenho: dos traçados tradicionais à gráfica computacional. Em 2002 houve uma reformulação buscando tornar a estrutura desta pós-graduação mais aberta e sensível ao processo de desenvolvimento da Informática Gráfica. Este desenvolvimento, para a área de Desenho, passou a sugerir uma revisão de conceitos e procedimentos, exigindo da comunidade acadêmica envolvida a inclusão e a apropriação da tecnologia informática, como condição fundamental para potencializar os meios de representação gráfica.

Por decorrência deste processo de "inclusão digital", a comunicação via Internet, entre alunos e professores, foi sendo naturalmente estabelecida, tendo em vista as facilidades oferecidas por esta rede para a interação e para o compartilhamento dos trabalhos digitais desenvolvidos no âmbito das disciplinas do Curso. Entretanto, não existia uma sistematização destas atividades didáticas não presenciais.Em 2002 foi disponibilizada, no âmbito da UFPEL, a plataforma para Educação a Distância TELEDUC. À exceção de duas disciplinas que compõem o módulo de Ensino e Pesquisa, as demais partiram para a experimentação desta plataforma, como apoio às situações de ensino/aprendizagem presenciais e também como espaço de extensão destas atividades.

Por outro lado, o próprio perfil dos alunos de pós-graduação fez intensificar a ocorrência de atividades didáticas não presenciais. Estes alunos necessitam de maior flexibilidade de horários, por estarem normalmente compatibilizando suas atividades profissionais com as de qualificação. E, como comentado anteriormente, a não homogeneidade de formação do corpo discente que compõe o Curso faz com que muitos alunos tenham que buscar informações complementares àquelas tratadas diretamente no período tradicional de aula, solicitando orientações extraclasse aos professores e colegas, onde a Internet passou a suportar esta comunicação. Inicialmente, esta dinâmica ocorria sempre de forma assíncrona.

Os materiais de apoio às aulas presenciais, normalmente em formato digital, foram sendo incrementados com discursos didáticos, textuais. Este incremento passou a beneficiar tanto aos alunos que eventualmente estão impossibilitados de assistirem à aula presencial, como ao processo de sistematização dos materiais do Curso.

Neste contexto, passou-se a construir uma trajetória em EaD.

\section{A metodologia adotada para implementação do Curso na modalidade em EaD}

A primeira iniciativa para intensificar a experimentação em $\mathrm{EaD}$ no âmbito do Curso foi de buscar a integração do Grupo GEGRADI (Grupo de Estudos para o ensino/aprendizagem em Gráfica Digital), composto por professores do Curso, com outros Grupos de Pesquisa que da mesma forma buscam estabelecer uma trajetória nesta área. Estas parcerias passaram a ocorrer a nível nacional e internacional, apoiadas pela rede ALFA/comunidade européia[1][2], rede PROSUL/CNPQ[3] e desenvolvimento de pesquisa junto ao centro de pesquisas da Faculdade de Arquitetura-Universidade de Sidney, Austrália, referente ao ensino a distância explorando Mundos Virtuais Tridimensionais como ambiente de ensino/aprendizagem. A parceria com o Grupo MAIDE, no âmbito da própria UFPEL, incrementou o assessoramento quanto às questões tecnológicas e de fundamentação em EaD.

Estas parcerias promoveram a revisão e seleção de um marco teórico e metodológico para guiar as estratégias didáticas que estruturam a experiência realizada. Resumidamente pode-se citar a contribuição de cada um dos projetos.

Da Rede ALFA-FADO [1], onde são compartilhadas as experiências em e-learning de dez instituições, latino-americanas e européias, adotam-se referências sobre as tecnologias em $\mathrm{EaD}$, além da 
caracterização do papel de tutor em EaD, como um novo agente promotor da interação entre professor/aluno, aluno/aluno e aluno/objeto de conhecimento.

As Redes ALFA T_GAME e T_GAME L3 [2] trazem referências conceituais e tecnológicas para a área de Gráfica Digital, a partir da contribuição de professores pesquisadores nas diversas áreas da Informática Gráfica.

A Rede ARQNET [3] apóia o desenvolvimento da infra-estrutura organizacional e tecnológica para o desenvolvimento da EaD. Foram trazidos os conceitos de mapas conceituais (Andler 1998) e de objetos de aprendizagem (Polsani 2003). Envolvendo pesquisadores na área de Informática na Educação, a rede adota referências como a abordagem cognitivista-construtivista (Piaget 1977) e a aprendizagem significativa (Ausubel 1978).

O Curso que atualmente apresenta-se com a estrutura demonstrada na Figura 1, ampliou as suas linhas de pesquisa, incluindo então uma linha específica para a área em questão: Ensino/aprendizagem de Gráfica Digital na modalidade à distância. Figura 1

Nesta estrutura de Curso somente duas disciplinas não são ministradas pelo Departamento de Desenho Técnico e Gráfica Computacional: as disciplinas de Metodologia do Ensino Superior e a de Metodologia da Pesquisa, que pertencem à Faculdade de Educação - UFPEL. O contexto do Curso, descrito anteriormente, onde professores e alunos apropriam-se das tecnologias informáticas como ferramentas de trabalho em Gráfica Digital, não incluía a realidade destas duas disciplinas, onde as estratégias e recursos didáticos referiam-se essencialmente aos métodos tradicionais de ensino, sem mediação da tecnologia nas situações de ensino/aprendizagem.

Desta forma, à exceção destas duas disciplinas, a metodologia proposta para a experiência-piloto, totalmente em $\mathrm{EaD}$, pode ser resumida a partir das seguintes estratégias:

- Disponibilizar o material didático utilizado nos momentos presenciais em formato digital no ambiente TELEDUC;

- Permitir o acompanhamento e participação de forma síncrona, por áudio e vídeo, via Internet;

- Acompanhar o desenvolvimento das atividades dos estudantes, através das ferramentas disponibilizadas na plataforma.

O experimento, no âmbito da disciplina "Metodologia do Ensino Superior", foi realizado no primeiro semestre de 2005. No âmbito da disciplina "Metodologia da Pesquisa", está sendo realizado neste segundo semestre. Cada um destes experimentos delimita um Projeto de Pesquisa, sendo que os resultados do primeiro subsidiam o segundo. A equipe de cada projeto está composta: por professores (da Faculdade de Educação), responsáveis pelas versões presenciais das disciplinas; por um grupo de alunas que, além de participarem da versão presencial, atuam como tutoras na versão não presencial da disciplina. Estas alunas, orientadas pelos professores referidos, estruturam os materiais didáticos em formato digital e promovem os fóruns de discussão sobre os temas desenvolvidos nos momentos presenciais; pelo grupo que assiste a disciplina à distância, via internet e ainda por professores que apóiam o projeto em relação às questões pedagógicas e tecnológicas específicas da $\mathrm{EaD}$.

A partir destas iniciativas, que passaram a disponibilizar todas as disciplinas do Curso na modalidade de $\mathrm{EaD}$, foi então possibilitada a realização de uma experiênciapiloto.

Optou-se por trabalhar com uma aluna a distância e uma aluna presencial no papel de aluno/tutor. Destaca-se que a aluna envolvida na situação a distância já havia sido bolsista de iniciação científica, vinculada aos projetos [1], [2], [3] que permitiram traçar 
uma trajetória de pesquisa em EaD. Este pressuposto foi para que houvesse a atuação da aluna como promotora do sucesso do experimento, apontando problemas e sugerindo soluções.

Os momentos didáticos, desta experiência, ocorrem, de acordo com a classificação de Alvarez(2005), de maneira assíncrona e também síncrona, nos quais a aluna interage com professores e colegas em tempo real. .Com o propósito de potencializar estes momentos exploram-se as diversas tecnologias disponíveis: uso de webcam, som, mensagens escritas, mundos virtuais bi e tridimensionais.

\section{0 ponto de vista do "aluno-tutor"}

O aluno-tutor é o agente que deverá efetuar a transposição das situações didáticas vivenciadas presencialmente, para o ambiente de ensino a distancia, de forma que estas promovam a aprendizagem dos alunos não presenciais.

$\mathrm{Na}$ experiência de Metodologia do Ensino e Metodologia da Pesquisa, o alunotutor assume as seguintes responsabilidades: informar os conteúdos das aulas presenciais a cada semana, direcionar as leituras obrigatórias, disponibilizá-las em alguns casos na íntegra no ambiente TELeduc, disponibilizar material de apoio, provocar discussões sobre os temas tratados nos fóruns de discussões, orientar na produção de trabalhos solicitados nas aulas presenciais e que foram também produzidos pelos alunos não presenciais.

Partindo de uma abordagem fundamentada na aprendizagem significativa (Jonassen, 1999), procurou-se estabelecer uma relação desta com os aspectos vivenciados na experiência de Educação à Distância do curso de Especialização em Gráfica Digital, para essas disciplinas. Jonassen (1996) caracteriza a aprendizagem construtivista como aquela que permite aos alunos aprender a reconhecer e resolver problemas, compreender novos fenômenos e definir e regular seu próprio processo de aprendizagem. Dentro dessa concepção devem estar as características de aprendizagem significativa que são: ativa; reflexiva; complexa; contextual; coloquial; interativa, de motivação e de regulação.

Considerando-se como positivos os aspectos relacionados à aprendizagem significativa, relacionam-se as seguintes ações como indicadoras das atitudes definidas por Jonassen:

(2) Interação do indivíduo com o ambiente e com os demais colegas - foi possível ao manipular as ferramentas, dispor de materiais de apoio, acessar portfólios individuais para compartilhar idéias e trabalhos produzidos, e fazer e receber comentários a respeito destes;

(2) Conhecimento ancorado no contexto - ao abrir-se fóruns de discussão para cada tema tratado, proporcionou-se ao aluno engajar-se numa discussão em que todos contextualizam as idéias apresentadas exemplificando e relacionando-as com suas experiências pessoais, situando-as dentro de um contexto, o que torna o aprendizado mais sólido ao referir-se a situações reais;

( ) Aprendizagem com motivação - a motivação pôde ser provocada através da forma como foram passados os conteúdos, com discussões nos fóruns criados, pois o aluno ao ter a seu alcance um conjunto de inserções de colegas discutindo sobre determinado tema, que praticamente formam um texto coletivo do assunto, se sente muito mais motivado para dar a sua opinião, a sua contribuição e participar.

Tais atitudes puderam ser comprovadas nas duas experiências tratadas neste estudo.

A diferenciação que se pode fazer de uma experiência para a outra é que na disciplina de Metodologia do Ensino as aulas presenciais eram baseadas em leituras de textos, em que se poderia ter uma livre interpretação e reflexão sobre estes, o que 
enriquecia as discussões nos fóruns, oportunizando ao aluno dar exemplos reais, próprios, vividos por ele. Esse fato potencializa a característica contextual, de uma aprendizagem ancorada no contexto real do aluno.

Já na experiência de Metodologia da Pesquisa a aula presencial era do tipo expositiva, em que as leituras para o aluno não presencial se procediam através de memórias de aulas e da apostila da disciplina, o que inibiu um pouco as discussões nos fóruns sem, portanto, chegar a comprometê-las profundamente. Também nesta disciplina a execução de trabalhos e a participação do professor nos fóruns de discussão e na avaliação das atividades diversas foi mais intensa.

Com relação à aprendizagem do aluno-tutor podemos destacar: na disciplina de Metodologia do Ensino o que mais contribuiu foi o fato de, após discutir temas fundamentais do pensamento educativo nas aulas presenciais, passarem a discuti-los novamente com as alunas não presenciais, muitas vezes sob outros enfoques. Isso proporcionou uma construção mais ampla, pois possibilitou que refletíssemos sobre opiniões de colegas das aulas presenciais e passássemos a discutir também sobre essas reflexões e opiniões com as alunas não presenciais, tornando o processo mais rico ao confrontar idéias e conclusões sobre elas;

$\mathrm{Na}$ disciplina de Metodologia da Pesquisa o aspecto positivo está sendo o fato de o professor participar ativamente dos fóruns de discussão, esclarecendo aspectos que o aluno-tutor não conseguiu deixar totalmente claro em alguns momentos e, em outras situações, confirmando a exatidão do esclarecimento feito pelo aluno-tutor. Também os comentários feitos pelo professor nos portfólios individuais a respeito dos trabalhos produzidos pelos alunos contribuíram na efetivação dessa aprendizagem.

Considera-se que o aluno-tutor, no contexto do Curso, tem desempenhado um papel fundamental na promoção das situações didáticas na modalidade à distância. Além de promover momentos que objetivam o desencadeamento de uma aprendizagem significativa para os alunos não presenciais, promove o seu próprio desenvolvimento, desenvolve habilidades como também para si.

\section{O ponto de vista do "aluno"}

$\mathrm{O}$ aluno que participou dessa experiência fez uma análise confrontando as duas situações didáticas vividas: os aspectos experimentados em disciplinas baseadas em encontros síncronos e aqueles detectados nas disciplinas na modalidade assíncrona. Através desse confronto procurou-se identificar os pontos positivos e negativos de cada situação em termos de aprendizagem.

Nos encontros síncronos, aqueles em que o aluno participa da aula ao mesmo tempo em que todos os outros alunos e o professor, estando em lugar diferente, utilizouse a videoconferência.

Nos encontros assíncronos, o aluno e os tutores e o professor, estão em lugares diferentes e acessam o material em períodos também diferentes, utilizando um ambiente na Internet, que nesse caso foi a plataforma TELeduc.

Considerando-se o contexto de aprendizagem do ensino à distância, traçam-se a análise das situações proporcionadas pelas duas modalidades, no seu favorecimento ao desenvolvimento de metodologias de educação continuada para o curso de Especialização em Gráfica Digital.

A modalidade síncrona, ocorreu nas disciplinas de Fundamentos de Informática Gráfica, Modelagem Visual e Modelagem Geométrica. O aluno se conectava via Internet nos horários de aula e participava das discussões, sendo que o material reproduzido nas aulas (slides), era disponibilizado anteriormente no TELEDUC, para o aluno poder acompanhar a exposição do conteúdo pelo professor. Nesta experiência houve problemas com o uso da câmera e, às vezes, do microfone, devido à lentidão da 
Internet nesses momentos. Em algumas aulas tornava mais fácil e ágil utilizar apenas a comunicação por texto, via MSN. Esse fato prejudicou o aprendizado naquelas circunstâncias em que o aluno ficava só com os slides e, dessa forma, necessitava recuperar com um encontro síncrono ou assíncrono com o professor, fora do horário de aula.

A modalidade assíncrona, ocorreu nas disciplinas de Metodologia do Ensino e Metodologia da Pesquisa e foi viabilizada pela participação do aluno/tutor que disponibilizava o material que havia sido usado na aula presencial na plataforma TELEDUC, principalmente textos, e o aluno estudava o material em horários diferentes que o horário da aula presencial e depois participava dos fóruns de discussão.

Os trabalhos de todas as disciplinas eram disponibilizados nos portfólios individuais de aluno ou de grupo no TELEDUC; os alunos presenciais também disponibilizavam os seus trabalhos nos portfólios individuais de maneira que todos pudessem ver os trabalhos dos colegas.

Em ambas as modalidades o aluno construía o seu conhecimento buscando outras informações que não estavam disponibilizadas, mas importantes para o aprendizado.

$\mathrm{Na}$ identificação dos pontos positivos e negativos, pode-se dizer que a modalidade assíncrona foi mais vantajosa em termos de continuidade de conteúdo, pois como o material já era preparado anteriormente e disponibilizado para ser estudado a qualquer hora, não havia prejuízos no caso de não haver conexão no horário de aula ou por conexões lentas.

Já na modalidade síncrona houve uma perda expressiva devido ao material disponível ser o mesmo material de apoio às aulas presenciais, constituído de slides.

Nas discussões da modalidade assíncrona perdia-se a continuidade de raciocínio, devido aos questionamentos serem respondidos em outro horário, o que também impunha ao aluno ter que voltar a ler todas as mensagens para fazer uma nova intervenção, em outro momento. Por outro lado, apesar de ser monótono, isso favoreceu a fixação e melhor entendimento dos diversos temas.

Nesta modalidade a flexibilização de horários para acessar o material e os fóruns, exige muita disciplina e comprometimento com a proposta pedagógica. Em virtude de não haver um horário definido, obrigatório, era freqüente o aluno passar longos períodos sem entrar no ambiente e sem participar, o que causou situações em que os tutores ficaram discutindo os assuntos entre si. Isto não ocorria na modalidade síncrona, já que, se não participasse no horário próprio, o aluno ficava prejudicado, situação que garantia, assim, a sua assiduidade.

\section{Discussão}

A partir dos relatos do aluno-tutor e do aluno não presencial, pode-se estabelecer uma discussão a respeito das percepções de cada um enquanto sujeitos e agentes do processo de aprendizagem da referida experiência em Educação a Distância.

Percebe-se que o aluno-tutor posiciona-se de uma forma mais positiva quanto ao processo de ensino/aprendizagem, o que se justifica por sua característica inerente que é o de ser o promotor das situações didáticas e incentivador da interação e participação dos alunos no ambiente. Essas ações proporcionam que o aluno-tutor tenha potencializado as suas condições de aprendizagem pelo fato de exigir que busque soluções para questionamentos dos alunos, que não foram resolvidos satisfatoriamente. Isso faz com que participe ativamente e profundamente em seu próprio processo de aprendizagem, regulando-o e criando condições mais sólidas para este se constituir.

Do ponto de vista do aluno não presencial o comprometimento já não é tão grande, mas mesmo assim, em muitos casos pode ser maior que o de um aluno presencial, pois 
também, como o aluno-tutor, tem que buscar seu conhecimento e informações para fazer as atividades ou solucionar questões além do conteúdo disponibilizado.

Cabe discutirmos quais as ações e características identificadas através dos dois relatos que poderão ser entendidas como mais significativas para a promoção da aprendizagem no ambiente de educação à distância do curso, a fim de proporcionar a implementação e sistematização dessas.

Entende-se que os elementos extraídos tanto do relato do ponto de vista do alunotutor como o do aluno não presencial, possuem dados fundamentais e que proporcionam intensificar-se o estudo na obtenção de parâmetros que promovam a metodologia adotada.

Acredita-se numa contribuição expressiva desses dois relatos: de um lado o aluno não presencial indicando que a experiência síncrona precisa melhorar, mas possui grandes vantagens por proporcionar a interação direta com o professor e colegas, e que a modalidade assíncrona foi mais vantajosa nessa experiência por fazer o aluno buscar mais o seu conhecimento e dispor de conteúdos melhores estruturados, além de participar mais ativamente de fóruns de discussões. Cabe ressaltar que essa condição foi atingida também graças ao trabalho dedicado do aluno-tutor, que a promoveu; do outro lado o aluno-tutor indica que a participação do aluno não presencial, trazendo questionamentos, seus entendimentos e relatos de experiências próprias, foi vital para o seu trabalho fluir e também para a sua própria aprendizagem.

Podemos extrair dessa discussão que ambos agentes (aluno e aluno-tutor) são sujeitos promotores da aprendizagem em Educação a Distância, e que um depende muito das ações do outro, produzindo, especialmente nesse caso, dados e parâmetros que indicam a pertinência da metodologia adotada, que passou a caracterizar um agente diferenciado: o aluno-tutor.

\section{Conclusões e perspectivas}

Tomando-se como base os relatos aqui produzidos pelo aluno não presencial e pelo aluno-tutor, pode-se concluir que:

(-) A escolha de um aluno presencial para atuar como tutor nesse projeto de $\mathrm{EaD}$, mostrou a validade de tal experiência na promoção da aprendizagem dos alunos não presenciais, assim como proporcionou ao aluno-tutor potencializar a sua própria aprendizagem;

(?) Essa metodologia também potencializou as condições de aprendizagem dos alunos não presenciais ao proporcionar uma interação aluno/tutor e aluno/aluno, o que propiciou a eles exercer, de fato, a autonomia na busca do conhecimento;

(?) A metodologia elegida para a experiência em EaD do Curso mostrou sua pertinência ao proporcionar que todas as disciplinas do currículo pudessem ser cursadas pelo aluno não presencial no primeiro e segundo semestres de 2005;

(-) Destacam-se os projetos das disciplinas de Metodologia do Ensino e Metodologia da Pesquisa por estas não possuírem, até o momento de implementação dessa experiência, nenhum conteúdo estruturado para $\mathrm{EaD}$, assim como também nenhuma experimentação do gênero, mesmo sendo disciplinas ligadas à Faculdade de Educação e disponibilizadas para vários cursos de especialização da UFPel;

(-) Visualiza-se a implementação de uma metodologia adequada à modalidade de Educação à Distância do Curso de Especialização em Gráfica Digital, a fim de sistematizá-la, em que o aluno-tutor passa a ter um papel diferenciado.

A perspectiva que se configura é de que se estabeleçam estudos contínuos de experimentação em Educação à Distância no Curso, de forma a traçar novos parâmetros que avaliem a atuação do aluno-tutor na promoção das situações didáticas. 
$\mathrm{O}$ aluno-tutor passa a ser o agente promotor, incentivador, mediador $\mathrm{e}$ interacionista que, juntamente com a participação dos alunos, auxilia na promoção do processo de ensino/aprendizagem.

[1] Rede ALFA FADO, http://www.alfafado.com Acessado em: 10 set.2005

[2] Rede ALFA T_GAME, http://t-game.ub.edu.ar Acessado em: 10 set.2005

[3] Rede ARQNET, http://iate.ufrgs.br/arqnet Acessado em: 10 set.2005

\section{Referências bibliográficas}

AAMC. Ambiente de Aprendizagem Mediado por Computador. Disponível em: www.niee.ufrgs.br/cursos/topicos2000/alunos2000/liliana/ambientes_aprendizagem.htm Acesso em: 10 jul.2005

ALVAREZ, Roger Loaiza. 2005 Disponível em: http://www.ugrs.es Acessado em: 10 jun. 2005

Andler, D.1998. Introdução às Ciências Cognitivas. São Leopoldo: Unisinos.

Ausubel, D., Novak,J. and Hanesian,H. 1978. Educational psychology: A cognitive view. 2nd edition. New York: Holt, Rinehart and Winston.

Jonassen, D. O uso das novas tecnologias na educação à distância e a aprendizagem construtivista. Brasília: Em Aberto, nº 70, p.70-88, ab./jun. 1996.

Piaget, J.1977. A Psicologia. Lisboa: Bertrand.

Polsani, P. R. 2003. Use and abuse of reusable learning objects. Journal of Digital Information. Disponível em: http://jodi.ecs.soton.ac.uk/?vol=3\&iss=4 m Acessado em: 10 mai. 2005 